УДК 34.343

DOI $10.21661 / \mathrm{r}-130484$

\title{
Л.Е. Чистова
}

\section{ПОНЯТИЕ И ЗАДАЧИ БАЗОВОЙ МЕТОДИКИ РАССЛЕДОВАНИЯ ПРЕСТУПЛЕНИЙ, СВЯЗАННЫХ С НЕЗАКОННЫМ ОБОРОТОМ НАРКОТИЧЕСКИХ СРЕДСТВ}

\begin{abstract}
Аннотация: в статье обосновывается необходимость разработки базовой методики расследования преступлений, связанных с незаконным оборотом наркотических средств в связи с тем, что данные преступления неразрывно между собой связаны, взаимообусловлены и отдельно друг от друга не могут совершаться в принциие. Сущуествующие отдельные частные методики разрабатывают рекомендации по расследованию конкретных видов преступлений, например, только контрабанды этих средств или их сбыта и между собой никак не связаны, в связи с этим проследить весь ияикл преступной деятельности от введения контролируемых средств в незаконный оборот до их сбыта невозможно, поэтому базовая методика расследования таких преступлений позволит проследить всю цеепочку преступных действий и выявить все обстоятельства, влияющие на полное и объективное расследование таких преступлений.
\end{abstract}

Ключевые слова: базовая методика, понятие, задачи, наркотические средства, расследование преступлений.

\section{L.E. Chistova}

\section{THE CONCEPT AND TASKS OF THE BASIC METHOD OF INVESTIGATION OF CRIMES RELATED TO ILLEGAL TRAFFICKING NARCOTIC DRUGS}

\begin{abstract}
: the article substantiates the need to develop a basic methodology for investigating crimes related to illicit trafficking in narcotic drugs due to the fact that these crimes are inextricably linked, interdependent and can not be carried out separately from each other in principle. The existing separate private methods develop rec-
\end{abstract}


ommendations for the investigation of specific types of crimes, for example, only smuggling of these funds or their sale and they are not connected with each other. In this regard, it is not possible to trace the whole cycle of criminal activity from the introduction of controlled means to illicit trafficking prior to their sale. Therefore, the basic methodology for investigating such crimes will allow us to trace the whole chain of criminal acts and to reveal all the circumstances that affect the full and objective investigation of such crimes.

Keywords: basic methodology, concept, tasks, narcotic drugs, investigation of crimes.

Вопрос о разработке единой базовой методики расследования преступлений, объединяемых в один род, неоднократно поднимался в криминалистической литературе [1; $3 ; 6]$. Объяснялось это тем, что при расследовании таких преступлений, как правило, возникают одинаковые следственные ситуации на различных этапах расследования и, в соответствии с этим, действия следователя по их раскрытию и расследованию, одинаковая.

Мы поддерживаем эту точку зрения и считаем, что такую базовую методику могли бы успешно использовать сотрудники правоохранительных органов, расследуя преступления по незаконному обороту рассматриваемых средств.

Эти виды преступлений имеют много общих признаков:

- общий предмет преступного посягательства;

- непосредственно незаконные действия, которые взаимосвязаны и не могут существовать одно без другого, т.к. представляют различные этапы преступной деятельности в их незаконном обороте;

- обстоятельства совершения таких преступлений, рассматриваемые в различных методиках расследования существующих видов преступлений;

- рассматриваемые виды преступлений совершаются практически одними и теми же лицами, независимо от их вида;

- возбуждение уголовных дел по данным категориям преступлений в подавляющих случаях происходит на основе материалов оперативной проверки; 
- при производстве следственных действий по всем видам рассматриваемых преступлений, используется одинаковая тактика;

- по делам данных категорий назначаются и проводятся одни и те же экспертизы, независимо от вида преступления.

В связи с этим, базовая методика позволит сотрудникам правоохранительных органов осуществлять расследование данных видов преступлений, начиная от поступления контролируемых средств на наркорынок до их сбыта.

В настоящее же время расследование таких преступлений осуществляется только за одно конкретное незаконное действие с этими средствами, за которое преступник задержан: непосредственный сбыт, только приобретение, перевозку, пересылку и т. д. И даже не выясняется источник поступления их не только в незаконный оборот, но и к определенному лицу, задержанному с этими средствами.

Базовая же методика, разрабатывая методические рекомендации по исследованию всех этапов преступной деятельности лиц, ею занимающихся, позволит проследить всю цепочку незаконных действий с контролируемыми средствами, эпизоды преступной деятельности, лиц, их совершающих и иные обстоятельства, влияющие на установление истины по делу.

Что касается понятия базовой методики расследования преступлений, в юридической литературе нам встретилось только одно определение М.В. Кардашевской, которая под этой криминалистической категорией предлагает «понимать систему научных положений и разрабатываемых на их основе рекомендаций по раскрытию и расследованию определенной совокупности преступлений, выделенных на основе уголовно-правовых и криминалистических признаков» [2, c. 30].

Базовую методику автор приведенного определения представляет универсальной схемой расследования определенной совокупности преступлений, содержать описание расследования таких преступлений, отражая особенности их расследования. Кроме этого они могут играть важную методологическую роль при разработках видовых методик расследования. 
Иными словами, базовая методика должна представлять собой общие положения, касающиеся расследования данных видов преступлений. Такие общие положения аккумулируют в себе типичные признаки, характерные для всех таких преступлений, позволяющих их объединить в единую совокупность. При этом базовая методика может разрабатывать рекомендации только типичного характера, используемые в расследовании преступлений, объединенный в определенный вид. Или, по справедливому замечанию Я.М. Мазунина такая методика должна ориентироваться на «создание комплексов методических рекомендаций большей степени общности, охватывающих несколько видов и даже родов преступлений, но совершаемых в определенных условиях места, времени либо лицами, характеризуемыми тем или иным общим отличительным признаком» [5, с. 221]. Особенным содержанием они наполняются при расследовании конкретного преступления или нескольких преступлений.

На наш взгляд, рассматриваемая нами методика, должна решать следующие задачи:

- систематизировать описание механизма преступлений объединенного вида;

- выявлять ситуации, в которых может протекать их расследование;

- разрабатывать модели деятельности следователя или дознавателя на протяжении всего периода расследования преступлений объединенного вида.

Что же касается базовой методики расследования преступлений, рассматриваемых категорий, по-нашему мнению, ее рекомендации по расследованию таких преступлений должны основываться на закономерностях, как их совершения, так и организации расследования.

О необходимости обращать внимание на такие закономерности обращал внимание еще И.М. Лузгин, рассматривая зависимость методик от следующих закономерностей: «объективных особенностей расследуемого преступления, его юридических признаков и условий совершения; совокупности объективных и субъективных факторов, влияющих на характер преступного деяния; особенностей конкретной ситуации, которые характеризуют обстоятельства совершения 
преступления и условия его расследования; структуры и организации правоприменительных органов, деятельность которых направлена на предотвращение и раскрытие и преступлений; содержания конкретной информации по делу, источников ее поступления, особенно на начальном этапе расследования» [4, с. 62-63].

Что же касается закономерностей базовой методики расследования преступлений, связанных с незаконным оборотом контролируемых средств, к ним, как нам представляется можно отнести следующие закономерности:

- связанные с возникновением, существованием и развитием преступной деятельности, в том числе и организованной и связанной с ней деятельностью по противодействию расследования;

- влияющие на механизм следообразования;

- последовательности незаконных действий, составляющие этапы преступной деятельности;

- выявления этой деятельности, в т.ч. влияющие на сбор доказательств;

- влияющие на возбуждение уголовного дела рассматриваемых видов преступлений;

- составляющие основу взаимодействия следователя или дознавателя с сотрудниками иных подразделений правоохранительных органов;

- влияющие на использование криминалистического обеспечения расследования преступлений, рассматриваемых видов;

- влияющие на определение направление расследования по делам данной категории на разных его этапах;

- влияющие на использование тактических приемов при проведении следственных действий;

- производства тактических комбинаций в отношении, как членов организованной преступной деятельности, так и лица, занимающегося преступной деятельностью в отношении контролируемых средств, единолично.

Следует отметить, что особенностью расследования уголовных дел о незаконном обороте рассматриваемых нами средств, является то, что практически все они, не зависимо от видов и организованности, возбуждаются по материалам 
оперативной проверки и без оперативного сопровождения до направления в суд, расследоваться не могут.

Однако, нам встретилось мнение, что при расследовании преступлений организованными преступными сообществами, следует разрабатывать две методики: одну - общую криминалистическую методику расследования преступлений, совершаемых организованными преступными сообществами (преступными организациями) и общую методику оперативно-розыскного сбора и накопления разведывательной информации о преступной деятельности организованных преступных сообществ [5, с. 231].

По мнению автора, обусловлено это рядом существенных факторов:

«Во-первых, особенностями организованной преступной деятельности, которые делают ее тщательно законспирированной, хорошо внешне и внутренне защищенной от разоблачения.

Во-вторых, малой эффективностью уголовно-процессуальных средств и, наоборот, большими возможностями оперативно-розыскных мер, в значительной степени негласного характера, в деле получения фактических данных, необходимых для возбуждения уголовных дела и успешного проведения следственных действий и расследования в целом.

В-третьих, тактико-методической и правовой общностью деятельности следственной и оперативно-розыскной. По существу они являются тесно связанными и взаимно дополняющими видами криминалистически-релевантной деятельности, фактически имеющими общие задачи и цели» [5, с. 231].

Мы полностью согласны с автором в этом вопросе. Но рассматриваемая им деятельность является предметом исследования совсем другой науки. Но поскольку, действительно, расследовать преступления, связанные с незаконным оборотом контролируемых средств без помощи оперативних сотрудников просто невозможно, да и основания для возбуждения уголовного дела по таким преступлениям получаются только оперативным путем, потому в базовой методике расследования таких преступлений обязательно должны находить свое отраже- 
ния закономерности взаимодействия следователяя или дознавателя с сотрудниками оперативних подразделений еще на стадии сбора информации о лице или лицах, занимающихся преступной деятельностью с даннями средствами при фиксации результатов оперативных мероприятий с целью последующего использования ее в качестве доказательств по делу, а также выявления каналов их поступления и сбыта. Однако при этом следует учитывать тот факт, что при использовании рассматриваемых закономерностей, следователь или дознаватель являются только консультантами и не могут вмешиваться в оперативную деятельность соответствующих сотрудников.

Таким образом, базовую методику расследования преступлений, связанных с незаконным оборотом наркотических средств, можно определить, как систему научных положений относительно вопросов, касающихся незаконного их оборота характеризующих его особенности и на их основе, используя закономерности криминальной деятельности в этой сфере и практики расследования преступлений, составляющих этапы преступной деятельности с этими средствами как единого целого, разрабатывает способы, приемы и методы их выявления, раскрытия и расследования во взаимодействии с сотрудниками других подразделений правоохранительных органов.

\section{Список литературы}

1. Гармаев Ю.П. Теоретические основы формирования криминалистических методик расследования преступлений: Монография / Ю.П. Гармаев. - Иркутск: ИЮИ ГП РФ, 2003. - 342 с.

2. Кардашевская М. Базовые методики расследования преступлений: Монография / М. Кардашевская // LapLambtrt. Германия. - 2012. - 139 с.

3. Косарев С.Ю. Криминалистические методики расследования преступлений: генезис, современное состояние, перспективы развития: Дис. ... Д-ра юрид. наук / С.Ю. Косарев. - СПб., 2005. - 401 с.

4. Лузгин И.М. Развитие методики расследования отдельных видов преступлений // Правоведение. - 1977. - №2. - С. 62-63. 
5. Мазунин Я.М. Проблемы теории и практики криминалистической методики расследования преступлений, совершаемых организованными преступными сообществами (преступными организациями): Дис. ... д-ра юрид. наук / Я.М. Мазунин. - Барнаул, 2005. - С. 221.

6. Субботина М.В. Криминалистические проблемы расследования хищений чужого имущества: Дис. ... канд. юрид. наук / М.В. Субботина. - Волгоград, 2004. $-421 \mathrm{c}$.

Чистова Любовь Евгеньевна - канд. юрид. наук, доцент, доцент кафедры криминалистики ФГКОУ ВО «Московский университет МВД России им. В.Я. Кикотя», Россия, Москва.

Chistova Lyubov Evgenievna - candidate of juridical sciences, associate professor of the Department of Criminal Sciences FSBEI of HE "Moscow University of the Ministry of Internal Affairs of the Russian Federation named after V.Y. Kikot”, Moscow, Russia. 